This item was submitted to Loughborough's Research Repository by the author.

Items in Figshare are protected by copyright, with all rights reserved, unless otherwise indicated.

\title{
Towards an integrated pedagogy of graphics in the United Kingdom
}

PLEASE CITE THE PUBLISHED VERSION

http://iridescent.icograda.org/index.php

PUBLISHER

Icograda $@$ The authors

VERSION

VoR (Version of Record)

LICENCE

CC BY-NC-ND 4.0

REPOSITORY RECORD

Harland, Robert G.. 2019. "Towards an Integrated Pedagogy of Graphics in the United Kingdom". figshare. https://hdl.handle.net/2134/11349. 
This item was submitted to Loughborough's Institutional Repository (https://dspace.lboro.ac.uk/) by the author and is made available under the following Creative Commons Licence conditions.

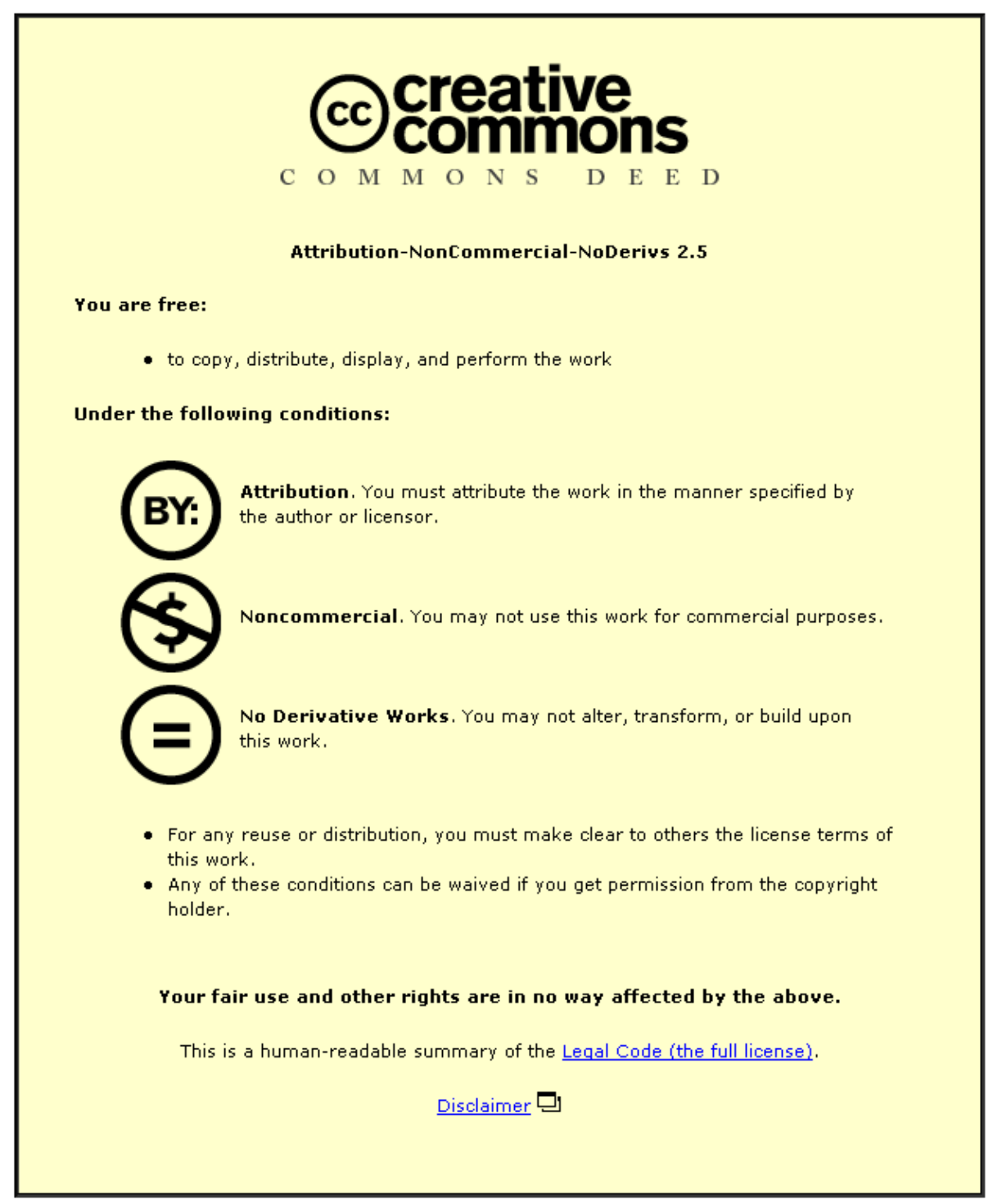

For the full text of this licence, please go to: http://creativecommons.org/licenses/by-nc-nd/2.5/ 


\title{
I R I D E S C E N T
}

\section{DESIGN EDUCATION}

\section{Towards an integrated pedagogy of graphics in the United Kingdom}

\section{Robert Harland}

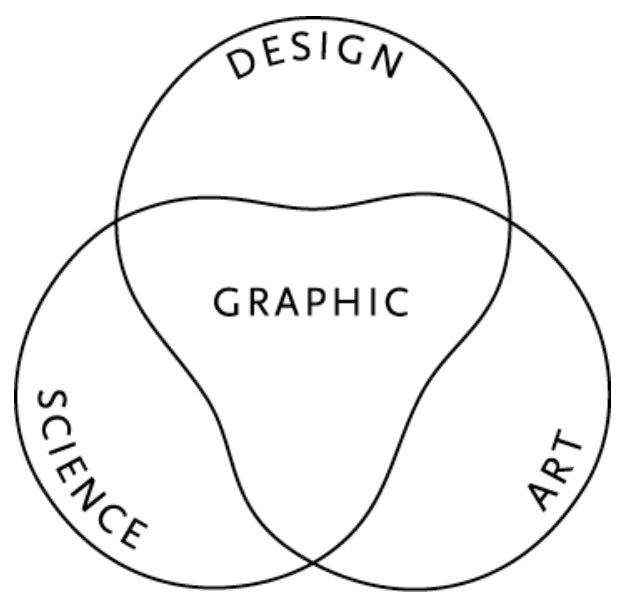

\begin{abstract}
In this discussion paper, graphic design, graphic science and graphic art are acknowledged, substantiating the need for benefits associated with a wider perspective on how students learn graphics in the United Kingdom. A case is presented for the adoption of a single word descriptor (compared to the many variants that have developed in the higher education sector) by discussing: the historical development of art and design in the United Kingdom; the widespread use of the term graphics; an emphasis on research neglect in a field that has diversified and expanded to become one of the largest groups of students in an enlarged university sector; a lack of national professional representation that has neglected the opportunity to link practice, pedagogy and research in a growing field. The inquiry begins with an overview, of the historical context, before an exploration into the recent expansion of a category of closely related words that originate from the same etymological source. Finally, consideration is given to the scope of influences that may form the basis of research into graphic method as a logical development of first-order design principles. The paper calls for renewed efforts, by graphics educators in the UK, to establish their own professional body to consolidate shared interest in graphics pedagogy between disciplinary perspectives.
\end{abstract}

Key Words: Graphics, Graphic Design; Pedagogy; Higher Education; Transdisciplinary 


\section{Introduction}

This paper brings together observations made after more than a decade of teaching graphic design, since 2001, in three contrasting university settings in the United Kingdom (UK) that are either teaching or research focused. Each university positioned undergraduate graphic design education in one of three ways: as a programme alongside other specialist programmes, for example, illustration and digital media; as an all encompassing graphic design degree, open and inclusive of a wide range of specialisms; and as a module in a programme called graphic communication. Such observations are inevitably tarnished with personal bias from a deep-rooted engagement with graphic design preceded by a fifteen-year period in professional practice. However, the paper attempts to balance and test opinions against empirical evidence, supported by the use of references, that substantiate the views expressed here and offer opportunity for further reading. Consequently, there is an interweaving of speculative argumentation, with factual evidence that seeks to establish relationships between a fragmented and complex set of relationships, that it may be better united under a single term: graphics. In this sense it is an transdisciplinary scoping study, that aspires to build a foundation for future research collaboration, in what is a fast changing UK higher education landscape, and further afield.

\section{Some historical context}

Much of the following discussion will benefit from a basic introduction to recent historical factors in the UK art and design higher education system. In the UK, graphic design now resides as a distinct discipline, but has been separate from university education until recently. The expansion of the university sector in the UK, during the two decades following 1992, has resulted in a closer proximity of some subjects, fields and disciplines that had never before been taught in the same institutional setting. Consequently, traditional art and design education is now also found in research-intensive universities such as Loughborough University, or the University of Dundee in Scotland, broadening the need to reclassify knowledge. The multidimensional nature of how knowledge has been categorized precedes an infusion of learning and teaching methods from 'artists' and 'designers' that have since added new approaches to those developed by the 'physical scientists' or 'literary intellectuals' that are said to reside at two 'poles' (Snow, 1964:4), often characterized as hard and soft disciplines. The physical sciences and engineering or history and languages (Donald, 1986:269-270), provide specific examples of this. These poles represent a perceived dilemma between science and art that depend on a 'systematic search' or 'intuitive creativity'. Some have looked to reconcile this quandary through design (Eder, 1995:127), but it is seldom acknowledged that design has been a fundamental aspect of formal 'art school' education predating many now established disciplines in academia.

Formal design education in the UK dates back to 1837 in London, and has evolved into the many schools of art and design now present in the University sector. This happened ten years after the formation of a University College in London, and predates the establishment of the Bartlett School of Architecture at University College London in 1841 (Rust et al., 2007:15). For most of the time since, art and design (from this point onwards referred to as a single disciplinary category) further developed independent of the university sector and its now mature research agenda. Over a similar period of time, art and design developed a mature studio practice culture with a distinct pedagogy, distinguished by a transformation, through what Thierry de Duve (1985:19-31) refers to as the traditional talent-métier-imitation (academic) model, towards the modern creativity-medium-invention (Bauhaus) model. During the nineteenth century art and design gradually established itself across the UK, and by the latter part of the century most large towns and cities had a school of art and design (ADM-HEA and NESTA, 2007:7), pre-dating many of the now well-established UK universities. According to Wayman and Brown (ADM-HEA and NESTA, 2007:8), these schools fostered a highly distinctive educational process that contributed to establishing the UK as a world-leader in innovation and creativity. They go on to say that art and design education in this form remained independent, as regional art colleges, until the late 1960s and early 1970s when most were amalgamated with new polytechnics. Polytechnics in turn became new universities in 1992, bringing the majority of formal art and design education into an expanded university sector, not seen before in the UK. This also exposed art and design to a different funding regime (national, rather than local authority controlled) and research performance reviews, every seven years, to determine additional government funding for research. Unsurprisingly, art and design research in the UK has since been in its infancy; however, the 2008 research assessment exercise (RAE) demonstrated positive signs in the development of a research culture suited to the specific nature of learning in the subject, and the 
forthcoming research excellence framework (REF) is much anticipated. How art and design research culture now integrates, with the longer established research community, is arguably the next important stage for art and design education. This paper attempts to contribute to this process by outlining some arguments that point the way towards sharing pedagogical perspectives in what might be better referred to using the abbreviated term 'graphics'. Before further justification for this shortened form, further consideration of the importance of graphic design in art and design education is necessary.

From the perspective of art and design, the provision of graphic design, in various guises, has remained robust through this recent period of integration, even though increased student numbers, due to expansion of the sector, has had a significant impact on the delivery of the subject. Graphic design has been able to accommodate much of this expansion through diversification into subspecialties and the rise of alternative degree award titles, for example, illustration, digital media, graphic communication, visual communication and others (Harland, 2007:5). This was actively encouraged by a review panel of graphic design studies in polytechnics and colleges prior to the change from polytechnic to university status (CNAA, 1990:41). However, there have been signs that this process is slowing and returning to something resembling what went before. Reasons for this might be that some schools of art and design are recognizing a loss of a diagnostic experience that traditional graphic design programmes provided. Also, the recognition that staffing small specialist provision, in subject areas that historically evolved around studio-based learning, is proving to be expensive by comparison to the traditional lecture-based learning and teaching methods that universities have utilized. A predicted drop in student numbers in 2012, due to demographic changes and economic factors due to increased student fees, are also having an impact, and programmes are regrouping through consolidation exercises that bring academic expertise back together. For example, in some institutions the sub-specialities that developed in the 1990s are now being reformed into more cohesive programmes, often with conjoined titles such as graphic design and illustration. To some who think of graphic design education as a diagnostic transdisciplinary experience this may appear as a misnomer.

Attempting to reflect a sense of academic alignment with other emerging disciplines, such as communication studies, some graphic design programmes have forsaken design and replaced it with communication in their title. Similarly, the more generic title visual communication has been given prominence in a small number of institutions. To some extent this is ironic because design is said to have matured as an academic discipline (Julier, 2008:1), arguably bringing much needed academic credibility to the art and design sector, and some have forsaken the term. One example of this is a UK university who ran a very successful graphic design programme in the 1980s. In the late 1990s it diversified into separate degree programme awards into graphic design, illustration and digital media, with little integration between the three, only to regroup under the collective banner of visual communication soon after the millennium. More recently, the same institution promoted a combined undergraduate/postgraduate learning experience leading to an MDes Visual Communication from three specialist pathways in graphic design, illustration and digital media. Now, it has returned to three separate degree awards in graphic design, illustration and digital media. This may be a natural development of academic interests, but it is also an indication of how graphic design has remained ill defined for some, when it is an holistic field that has continued to prosper despite the attempt of specialisms to develop independently. In 1990, the CNAA review team could not define graphic design as much more than a convenient way to group specialisms:

... the generic title 'graphic design' is understood to apply to the broad range of specialism's contributing to visual design for communication media, whether printed or electronic, static or time-based. The media include print (e.g. books, magazines and promotional material) and electronic media (e.g. computer graphics and video). The technical specialisms include illustration, typography and photography. Its applications may be informative, persuasive or recreational, and include information design, advertising design, corporate identity design, packaging design and publishing design. (CNAA, 1990:13)

It seems that, unable to define graphic design more succinctly, it has been convenient to adopt other phrases, such as visual communication. Yet visual communication is attributed to a significantly larger community of educators than reside in art and design (Harland 2011a:206-219), and the interdisciplinary diversity gains that may have been intended are yet to be seen, if current displays of work by art and design degree students is anything to go by. At the D\&AD New Blood exhibition of 
graduate work in London, June 2012, the range of programme titles shown in Table 1 demonstrates diversity emerging from what, using the above CNAA definition, may have constituted graphic design two decades ago.

Table 1: Programme titles of exhibitors at D\&AD Young Blood 2012, London

Art \& Design: Graphic Design

Art \& Design (Visual Communication Design) Graphic Arts

Graphic Design

Graphic Design/Graphic Design \& Photography

Graphic Design and Illustration

Graphic Design and Illustration

Graphic Design \& Typography

Graphic \& 3D Digital Design

Graphic \& Communication Design

Graphic Communication Design

Graphic Information Design

Graphic Communication

Communication Design

Visual Communication

Visual Communication: Graphics and Illustration

Photography

Illustration

Illustration \& Animation

Illustration and Visual Communication

\author{
Advertising \\ Advertising Design \\ Advertising: Creative \\ Advertising and Brand Design \\ Creative Advertising \\ Advertising Specialist \\ Design for Publishing \\ Design \& Visual Arts \\ Design for Communication \\ Design for Visual Communication \\ Multimedia \\ Graphic and Multimedia Design \\ Digital Media Production \& Contemporary Arts Practice \\ Motion Graphics \\ Motion Graphics and Animation \\ Interactive Media Design
}

The point being made here is that graphics, in its many guises, is clearly central to art and design in higher education, and design is one aspect of that. One possible interpretation, of recent developments, is to believe that the ambiguity associated with the term design (Heskett, 2005:1-7), is now being replaced with the ambiguity associated with the term communication (Williams, 1983:7273). This should not be surprising as graphic design is listed as a subspecialty of visual communication and through this the subject is linked to a wider range of topics as diverse as architecture, linguistics and archaeology (Moriarty and Barnbatsis, 2005, p. xviii). The same trend is reported to be happening in Australia, where communication design is said to be replacing graphic design, but without any clear understanding about what communication design is or might be (Vaughan, 2008). The trend is supported with generalizations that graphic design has evolved to visual communication, and still further to communication design (Buchanan 2001:10). However, such claims are unsupported with factual evidence and the list above suggests this is not the case in the UK. There are clearly instances where this has happened, but these are arguably dwarfed by the establishment of new graphic design programmes worldwide, benefitting from increased access to subject literature, in countries, like Malaysia, that do not have an established tradition of art and design in higher education. Different traditions clearly exist and continue to develop, but this requires deeper research to determine how graphic design is developing worldwide, and how significantly other specialist programmes and non-specialist programmes differ.

This may be difficult to achieve, from the UK perspective, without the active presence of a professional body that can bring together the various fragments and scope of the field. This has been seriously lacking in recent decades. Whereas many subjects, studied in UK higher education, benefit from a close relationship with a professional body, society or subject association that aspire to integrate the needs of practice, education and research, at present graphic design does not. Those organizations that have aspired to demonstrate some commitment to linking practice, education and sometimes research, generally lack the breadth and depth to affect future direction of the subject. They have either failed to maintain a level of consistency and specificity (Chartered Society of Designers/CSD); are too industry focused (Design and Art Direction/D\&AD) and vulnerable to expansion and contraction (see Design week, 13 August 2009); are too specialized (Association of Illustrators/AOI or the International Society of Typographic Designers/ISTD); favor a different name and emphasis (Information Design Association); or have experienced significant decline, reorganization and unfulfilled potential (The Design Education Association/DEED) as yet. Each has developed its own particular concerns, but few can be said to have galvanized an agenda for the field over time that scopes the higher education landscape. Similarly, none have been able to be influential 
in the way those associated with general education have, such as the National Society for Educators in Art \& Design (NSEAD) or Design and Technology Association (DATA). In research, organizations, such as the Design Research Society (DRS), have been distant from day-to-day practice and education in graphic design. The International Council of Graphic Design Associations (ICOGRADA) is no longer closely associated with educational activities in the UK, since the death of significant graphic design pioneers such as F.K. Henrion or Alan Fletcher, compared to activities in the 1970s and 1980s.

The consequence of this is that graphic design has been significantly underrepresented in recent decades, and this is disproportionate to the size and scope of the subject in higher education in the UK. It is therefore unsurprising the subject has not figured by name in research reviews across the art and design sector (Rust et al., 2007:31). Note, for example, the list of headings used to classify research degrees by subject group over the thirty year period since the mid-1970s (Fisher and Mottram, 2006:8). These include architecture, craft, design subjects, fine art, photography and film, other creative art and design, textiles and fashion, and visual communication.

Considering the popularity, scope, and potential reach of activities associated with graphic design, there is a perceived need to unite a disparate set of descriptors, activities and loose affiliations, for the benefit of a large academic community of students and educators. If art and design matures as a university discipline, the heritage associated with graphic design offers potential to cross disciplinary boundaries. However, it is hypothesized here that the fragmentation, that has come with expansion, may require graphic design to reconsider and reside within an enlarged disciplinary context, that is not called visual communication, but an abbreviated single discipline of graphics that also acknowledges design. The rest of this paper considers a case for a single word to represent a distinct, but increasingly widespread activity gaining in recognition that is already used beyond art and design. For example, Jacques Bertin used the term in the title of his book Semiology of Graphics (1983), though the scope of his project is limited compared to the arguments presented in this paper, being concerned only with diagrams, networks and maps.

\section{A case for the single term graphics}

Since the early 1990s, it seems we have been increasingly living in a graphic age, and this is set to continue. On Saturday, 8 October, 2011, a new word entered public consciousness in the UK. The Guardian newspaper published an article with the headline 'Graphene: it's thin, grey and it might just be the future' (Jha and Milmo, 2011:21). In the article, the Chancellor of the Exchequer for the UK, George Osborne, is quoted as saying: 'It's the strongest, thinnest, best conducting material known to science, to be used in everything from aircraft wings to microchips'. This is also remarkable for etymological reasons. First, little more than a decade in, the twenty-first century is predicted to benefit significantly from a substance that derives its name from the Greek graphé. Second, it further acknowledges a rise in prominence of dictionary words and phrases since the early 1980s, from the same source. Then, in between grape and grapple, the single word graph represented a number of variants (Kirkpatrick, 1983). Within a relatively long entry for graph could be found descriptions for 26 derivatives that include graph'ite (a mineral composed of carbon), graphic formula (chemical formula), grapheme (letter of the alphabet) and graphic arts (painting, drawing and engraving). Significantly, the incorporation of all these within the overarching graph represented the nature of many words that straddle science and humanities, the hard and soft academic disciplines.

In the early twenty first century the Oxford Dictionary of English (Soanes and Stevenson, 2005) deem the same words and more as worthy of independent entries, listing twenty-one words, phrases and terminals between grapevine and grapnel: graph, ...-graph, ...grapheme, ...-grapher, ...graphic, ...graphic, ...graphicacy, ...graphical, ...graphical user interface, ...graphic arts, ...graphic design, ...graphic equalizer, ...graphic novel, ...graphics, ...graphics card, ...graphics tablet, ...graphite, ...graphology, ...graph paper, ...graph theory, ...-graphy. Further adoptions of the root word also continue in specialist academic dictionaries. For example, graphic analysis, graphic individuality, graphic language, graphic rating scale, graphodyne, graphometry, and graphorrhoea appear in the Dictionary of Psychology (2001). These many derivations suggest there has been something resembling a graphic revolution over the twenty-year period spanning the turn of the millennium, but there remain inconsistencies and subtle differences that lead to confusion. For example, graphic arts noted above as being about painting, drawing and engraving differs from The Thames and Hudson Dictionary of Art and Artists (1994:157) definition of graphic arts that dismisses painting and excludes drawing, but includes silk sceen. 
The emergence of graphic design in such lists is late recognition for a subject that since the late 1960s has been taught in higher education schools of art and design, though remained relatively unknown until the early 1990s (Barnard, 2005:1-11). Then, a specialist dictionary definition with authoritative content about the European-American development of the subject claimed it to be the integrated use of typography, illustration, photography, and printing for persuasion, information or instruction (Livingstone and Livingstone, 1992:90). This comparatively limited, but useful, definition appears to have stayed in tact as a general understanding of graphic design, more generally defined by the Oxford Dictionary of English (2005) as a noun meaning 'the art or skill of combining text and pictures in advertisements, magazines, or books'. However, in graphic design practice, the close association of subtle references that may span the process of conceiving, planning, organization, mark making, and impact continue to make graphic design a difficult term to fully qualify. It is further complicated by an attention-seeking dimension that suggests it may also 'shock', as in the way Benjamin ([1936] 2008:20) uses the word 'graphically', or in the way McLuhan and Fiore (1967) propose, that art translates culture. Karel van der Waarde's failure to discover an exact definition across the plethora of books, surveys, awards, and critical reflections on the subject substantiates this (2009:7-10).

Popular dictionary sources also refer to the stand-alone term graphic by relating it to visual art drawing, engraving, lettering - as well as 'clear and vividly explicit details'. Whereas graphics is said to be the 'products of graphic arts' - in 'commercial design or illustration, or diagrams'. Clearly this can mean the kind of lithographic, etching or lino-cut outcomes that will be found in art historical contexts, where it is synonymous with image and visual artifact (Elkins, 1999:255). With the addition of design to the graphic, a further interrogation of definitions leads the debate to broaden further with design's emphasis on 'planning', and further to what has been referred to by Bruce Archer as 'modelling' [sic] (1976:12). Taken separately graphic and design may utilize a range of similar and differing modeling practices. Dictionary definitions invariably define the singular term graphics as something relating to visual art, and in the case of often complex and subtle distinctions, that span scientific as well as artistic interest; questions, therefore, continually arise about the nature of graphic design. The arguments presented here may therefore be more suitably placed within a discipline of graphic knowledge that distinguishes, at a basic level, between science, art and design. But, contrary to the discussion thus far, this proposition suggests there is a distinction between art and design.

Since the 1960s, in the development of design research, it has been acknowledged that the distinction between art and design may well be a matter of personal preference. For example, before settling on the term Design 'with a capital D' to name a third area in education alongside science and humanities, Bruce Archer professed 'the Arts' as an ideal name (1976:11) but claimed it was too associated with humanities. In this sense, graphics may be regarded a branch of design, perhaps thought of in the same sense that physics is regarded a branch of science (familiar to both general and higher education), but it may no longer be necessary to state the relationship between graphics and design, if graphics seeks to gain recognition across science, design and art. Graphics can be said to be concerned with the nature and properties of what Elkins (1999:91) calls 'writing, pictures and notation'. In this abbreviated sense graphics may best represent the specialist subjects that have developed in art and design in the UK since 1969, from a subject base known as graphic design. Then, core art and design subjects were classified as fine art, graphic design, three dimensional design, textiles and fashion (Drew et al., 2008:45). Table 1 demonstrates the diversity of graphics across the art and design sector in the UK, and the frequent use of graphic, or graphics, as a common denominator in undergraduate programme titles. It appears to have grown into a significant majority in hybrid names that students choose from (Harland, 2007). Within art and design there is an obvious link to the 'typographic' and the 'photographic'. Beyond this, it also extends to subjects as diverse as language studies and geography, through their respective use of terms such as 'graphicacy' and 'graphetics' (Harland 2011a:160-206).

It has been the intention here to understand and explicate an intricate set of relationships and propose these reside under the moniker of graphics. However, objections to the use of a single term may come from those who acknowledge the term graphics as being 'vacuous' and 'self-referential' (Stiff, 2009, p. 10). Though, such opinions are often unsubstantiated, and too often reinforce a lack of unity when the opposite may be required, to understand the wider needs of society, and the new problems that do not fit comfortably within existing disciplinary structures. This need for a holistic approach is the basis of the argument made by Richard Buchanan (2001) when he suggests: 
We possess great knowledge, but the knowledge is fragmented into so great an array of specializations that we cannot find connections and integrations that serve human beings either in their desire to know and understand the world or in their ability to act knowledgeably and responsibly in practical life. While many problems remain to be solved in the fields that currently characterize the old learning-and we must continue to seek better understanding through research in these areas-there are also new problems that are not well addressed by the old structure of learning and the old models of research.' (Buchanan, 2001:6)

Despite these known problems of classification that hinder the 'domain of images' (Elkins, 1999:82), the argument for a singular use of the term graphics to link across general, further and higher education is timely. It may help bridge discussions about 'graphic skills' (Stiff, 2009:11) and the kind of 'contemporary scientific and mathematical graphics' noted by Elkins (ibid:222). Clearly, graphics does not exclusively belong to art and design: there is a graphic science, graphic art and graphic design that may benefit from closer association in academic research to generate new learning and problem solving opportunities. If the argument for adopting the term graphics to represent a wide-ranging academic discipline is agreeable, there must be a need to better understand how it is taught and learned across different academic disciplines. This is especially important given the possible size and scope of application.

There is a strong case for interdisciplinary gains in graphics, especially for those who teach the subject as part of a discipline beyond art and design and for graphic design students who wist to extend their interests to academic disciplines beyond art and design. Graphic design is one of the most popular subjects in the art and design higher education in the UK. This in part is because in professional practice graphic designers have many opportunities that can benefit those who come into the workplace from a non-traditional art and design route. There is a well-established graphic design professional practice. the subject benefits from increasing significance in general education.

Furthermore, established academic disciplines such as geography use similar processes of image creation and increasingly we see emerging recognition in science subjects as diverse as information science, cognitive science and mechanical engineering. The evidence for this is clear.

A search on the UCAS website (the service that organizes applications to UK higher education courses), reveals more single subject graphic design programmes in the UK than any of the other core subjects in art and design. This seemingly feeds a healthy demand in professional practice, as confirmed by a Labour Force Survey looking at UK Employment, by Design Occupation, which suggests that graphic design accounts for 93,000 design associate professionals out of 136,000 (Prior et al., 2007:3). Graphics is also central to the new 'Diploma in Creative and Media' (2008:20) for 14$19 \mathrm{yr}$ olds in the UK, as a core subject in 'Crafts, Creative Arts and Design' (one of four categories within 'Arts, Media and Publishing') (QAA, 2009). In Geography 'graphicacy' is a long established key method (Clifford and Valentine, 2003:344-368) and thought by some to be the 'most distinctively geographical form of communication' (Boardman, 1983, page not numbered). Graphic design is also named as a core module for research-intensive University undergraduate programmes in information science, (such as 'Publishing with English' and 'Publishing with e-Business' at Loughborough University). Furthermore, in 2008, Cambridge University Department of Engineering advertised for a 'PhD Studentship in Graphic Elicitation' (www.jobs.ac.uk/jobs/FH557/).

With this in mind, the key question emerges: what is the scope of activities associated with practice that might inform the extension, and understanding, of what has be referred to as 'graphic method' (Bertin, [1967] 2011) or 'graphical method' (Biggs and Buchler 2008:5-18), and related to the rise of visual method (Harland, 2011b)? If art and design is a useful starting point for answering this question, van der Waarde (2009) identifies a diverse and sophisticated range of activities undertaken by graphic design practitioners (ibid:60-61) that may help direct an interdisciplinary discussion about 'method'. See Table 2. These activities number twenty-seven in all, and include the familiar subjects of typography, illustration, photography, advertising, as well as animation, infographics, website design, programming, copywriting, visual research, film production and more. However, this does indicate the potential scope for research in a graphics discipline alongside what might be influenced by a scientific, artistic and 'designerly ways of knowing' (Cross, 2005). 
Table 2. The activities of graphic designers. Source: van der Waarde, 2009a:60-61

$\begin{array}{lll}\text { Illustration } & \text { Infographics } & \text { Marketing } \\ \text { Photography } & \text { Font design } & \text { Communication strategy } \\ \text { Typography } & \text { Desktop publishing } & \text { Usability } \\ \text { Copywriting } & \text { Film production } & \text { End user research } \\ \text { Image processing } & \text { Website design } & \text { Visual research } \\ \text { Animation } & \text { Graphic art } & \text { Visual strategy } \\ \text { Audio-video } & \text { Spatial design } & \text { Concept development } \\ \text { Programming } & \text { Advertising } & \text { House style management } \\ \text { Author } & \text { House style design } & \text { Project organization }\end{array}$

\section{Conclusion}

A fragmented use of terminology, in a relatively new university discipline, may hamper any attempt to establish a broad unified agenda for research, especially when the mode of knowledge production includes "the relationship between practice and research, a focus on 'making' as well as thinking, and collaborative practices that recognize the need for negotiation, and distinguish problem setting from problem solving" (Moore, 2009:20). This is a challenge for graphic design and the many programme titles that have evolved over the previous two decades and are historically closely related. To the wider university community, with whom much potential exists for research collaboration, this may prohibit a clear sense of managing expectations. Graphics is already located in many of these disciplines, either as a practice, phenomenon or method (for example, Infographics in Information Science, or Cartography and Graphicacy in Geography). Questions arise, such as: What constitutes the graphic'? How do students learn graphics in these disciplines compared to a student in art and design? What differentiates the graphic knowledge of a geographer compared to a designer? These are some central question that will benefit from pedagogic research. Potential benefits might include: enhanced student learning experiences; research collaboration for staff; the possibility for better use of human and physical resources; and an improvement in the objects, products, services and things used in everyday life as well as professional environments.

Some who hold on to traditional views in graphic design education may interpret these reflective and projective arguments with caution. But, as the design research community respectively pursues 'interaction' and 'environmental' design as third- and fourth-order design, that will 'transform the design professions and design education' (Buchanan 2001:6), graphic design as a 'first-order' principle must also respond. Some believe '[i]t is difficult to see how design thinking can go back to its earlier centers of attention without a sustained period of exploration of interactions and environments' (Buchanan, 2001:6). This suggestion may be more related to theory and less about the material practices traditionally associated with graphic design. It also presupposes that we know all there is to know about first (graphic) and second order (industrial) design thinking. Consequently, this paper calls for the development of research agenda in graphics that is transdisciplinary, to ensure that if there is a return to earlier ideals, such a return is welcomed, aligned, familiar with contemporary debates across the wider domain of knowledge through its contribution to them, and perhaps, more appropriately, known through the singular use of the term graphics.

How might this be achieved? One part of the answer is to suggest that there is much need for an organization in the UK that puts graphics education first, to replace the lost efforts of previous generations. For example, an assembly of graphics educators could establish an association of graphics educators (perhaps called 'NewAGE'). This may go towards exploring the potential for stimulating academic debate, exchanging ideas about learning, teaching and scholarly activity, liaising with public and professional bodies, and lobbying for the interest of the sector and sharing good practice. This should not be confined to art and design, though may be initiated from within the discipline, as has been the case by other subjects such as the Association of Fashion and Textiles courses. It must be a significant concern for all involved in graphics education that no such body yet exists for graphics, regardless of function. 


\section{References}

ADM-HEA \& NESTA. 2007. Creating Entrepreneurship: entrepreneurship education for the creative industries. The Higher Education Academy Art Design Media Subject Centre and the National Endowment for Science, Technology and the Arts.

Archer, B. 1976. The Three Rs. In: Archer, B., Baynes, K. \& Roberts, P. (eds.) A framework for Design and Design Education: A reader containing key papers from the 1970s and 1980s. Wellesbourne: The Design and Technology Association.

Barnard, M. 2005. Graphic Design as Communication, London, Routledge.

Bertin, J. [1967] 2011. Semiology of graphics: diagrams, networks, maps, W. J. Berg, translator, New York and London: Esri Press.

Benjamin, W. [1936] 2008. The work of art in the age of mechanical representation, J. A. Underwood, translator, London: Penguin Books.

Biggs, M. \& Buchler, D. 2008. 'Eight criteria for practice-based research in the creative and cultural industries', Art, Design \& Communication in Higher Education, 7: 1, pp. 5-18, doi: 10:1386/adche.7.1.5/1.

Boardman, D. 1983. Graphicacy and geography teaching, Beckenham, Croom Helm Ltd.

Buchanan, R. 2001. Design Research and the New Learning. Design Issues, 17, 3-23.

Clifford, N. J. \& Valentine, G. (eds.) 2003. Key Methods in Geogaphy, London: SAGE Publications Ltd.

CNAA. (1990). Vision and change: a review of graphic design studies in polytechnics and colleges. Council for National Academic Awards, London.

De Duve, T. 1985. "When form has become attitude - and beyond", in Z. Kocur and S. Leung, (eds.), Theory in Contemporary Art since 1985. UK: Blackwell Publishing, pp. 19-31.

Cross, N. 2006. Designerly ways of knowing, London: Springer-Verlag.

Donald, J. G. 1986. Knowledge and the university curriculum. Higher Education, 15, 267-282

Drew, L., Last, J., Lewis, S. \& Wade, S. (eds.) 2008. The student experience in art and design higher education: drivers for change, Cambridge: Jill Rogers Associates Limited.

Eder, E., W. 1995. Engineering design - art, science and relationships. Design Studies, 16, 117-127.

Elkins, J. 1999. The domain of images, New York, Cornell University Press.

Fisher, T. \& Mottram, J. Researching the Research Culture in Art \& Design: The Art and Design Index to Theses, In: Friedman, K., Love, T. \& Côrte-Real, eds. Design Research Society International Conference 2006, 'Wonderground', 1-4 November 2006 Lisbon, Portugal. CEIADE, 131.

Harland, R. G. 2011a. Graphic design as urban design: towards a theory for analysing graphic objects in urban environments, PhD Dissertation, The University of Nottingham, Nottingham. Full text: https://dspace.Iboro.ac.uk/dspace-jspui/handle/2134/10050

Harland, R. G. 2011b Graphic method as visual method. In The Second International Visual Research Methods Conference, Abstract, The Open University, Milton Keynes, UK, p.36, Full text: hhtp://www.visualmethods.org/documents/IVM-Full-Programme.pdf

Harland, R. G. 2007. Redefining the plural domains of graphic design and orientating the subject towards a model that links practice, education and research. International Association of Societies of Design Research: Emerging Trends in Design Research, The Hong Kong Polytechnic University, 12-15 November. Hong Kong.

Heskett, J. 2005. Design: a very short introduction, Oxford, Oxford University Press.

Jha, A. \& Milmo, D. 2011. Graphene: it's thin, grey and it might just be the future. The Guardian. London and Manchester. Saturday 8 October, p. 21.

Kirkpatrick, E. M. (ed.) 1983. Chambers 20th Century Dictionary, Edinburgh: W \& R Chambers Ltd. 
Livingston, A. \& Livingston, I. 1992. The Thames and Hudson Dictionary of Graphic Design and Designers, London, Thames and Hudson Ltd.

McLuhan, M., and Fiore, Q. (1967). The medium is the massage, London: Penguin Books Ltd.

Moore, G., 2009. (Re)defining interdisciplinarity: (re)forming universities. In: Interrogations: Creative Interdisciplinarity in Art and Design Research: Proceedings of AHRC Postgraduate Conference 2009, pp. 13-24. http://hdl.handle.net/2134/5369.

Moriarty, S. \& Barnbatsis, G. 2005. From an Oak to a Stand of Aspen: Visual Communication Theory Mapped as Rhizone Analysis. In: Smith, K., Moriarty, S., Barbatsis, G. \& Kenney, K. (eds.) Handbook of Visual Communication: Theory, Methods, and Media. Mahwah: Lawrence Erlbaum Associats, Inc., Publishers.

Prior, S. D., Schen, S.-T. \& Karamanoglu, M. The Problems with Design Education in the UK. In: International Association of Societies of Design Research Conference, 12-15 November 2007, The Hong Kong Polytechnic University. 12.

QAA. 2009. Qualifications and Curriculum Authority sector subject area/tier for arts, media and publishing [Online]. Qualifications and Curriculum Authority. Available: http://www.qca.org.uk/qca_8507.aspx [Accessed 08 Jan 2009].

Read, H., and Stangos, N. 1994. The Thames and Hudson Dictionary of Art and Artists. London: Thames and Hudson.

Reber, A. S., Reber, E. S. 2001. The Penguin Dictionary of Psychology, (Third Edition), London: Penguin Books.

Rust, C., Mottram, J. \& Till, J. 2007. Practice-Led Research in Art, Design and Architecture. Arts \& Humanities Research Council.

Skillset 2008. Diploma in Creative and Media: Companion Document Skillset: The Sector Skills Council for Creative Media.

Snow, C. P. 1993 [1964]. The Two Cultures, Cambridge: Canto (Cambridge University Press).

Soanes, C. \& Stevenson, A. (eds.) 2005. Oxford Dictionary of English, Oxford: Oxford University Press.

Stiff, P. (ed.) 2009. Modern typography in Britain: graphic design, politics and society, London: Hyphen Press.

van der Waarde, K. 2009. On graphic design: listening to the reader, Avans Hogeschool Research Group Visual Rhetoric AKV | St. Joost.

Vaughan L. What are the implications of the shift from Graphic Communication to Communication Design? In: New Views 2: Conversations and Dialogues in Graphic Design. An International Symposium defining graphic design for the future. 9-11 July, 2008 London College of Communication, University of the Arts London, United Kingdom.

Williams, R. 1983. Keywords: a vocabulary of culture and society, London, Fontana Press.

\section{Acknowledgements}

The author acknowledges the helpful comments and suggestions from the editor and peer reviewers about the structure of earlier versions of the paper.

\section{About the Author}

Dr. Robert Harland is a lecturer in the School of the Arts, Loughborough University, where he chairs the School's Learning and Teaching Committee. His research and teaching focus is on the relationship between typographic, graphic and urban design (the topic of his PhD), and he commits a third of his time to pedagogic research. He regularly contributes to design research conferences and journals and is an International Society of Typographic Designers Education Committee member. Prior to entering academia, he gained industry experience in London over a fifteen-year period that spanned design consultancy activity and running his own design practice for ten years, working with a wide range UK and European clients. 


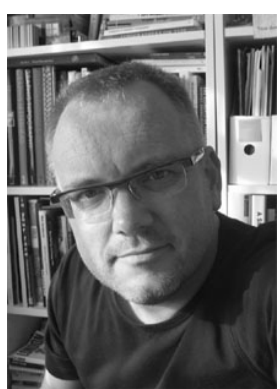

\section{Contact Information}

Name: Robert Harland

Title: Doctor

Address:

Loughborough University

School of the Arts

Loughborough

Leicestershire

LE11 3TU

E: r.g.harland@lboro.ac.uk

The above text is the 'accepted for publication (author final)' version.

The article citation and location is as follows:

Harland, R. G. (2012). Towards an integrated pedagogy of graphics in the United Kingdom. Iridescent, Icograda Journal of Design Research, 2(1).

http://iridescent.icograda.org/2012/12/08/towards_an_integrated_pedagogy_of_graphics_in_the_united_kingdom.php 